\title{
ENDEMIC SOUTH ASIAN PRIMATES UPDATED ON THE 2004 IUCN RED LIST
}

\author{
Sanjay Molur and Sally Walker
}

This issue is dedicated to langur taxonomy, of a group that was thought of as a simple, large population of a common species of Hanuman/ Common Langur found throughout India. The Conservation Assessment and Management Plan (CAMP) Workshop for South Asian primates was an education of sorts to the primatologists of the region who were unfamiliar with the species/subspecies definitions and distributions as proposed by the IUCN SSC Primate Specialist Group (PSG) working document, or the latest publication of Colin Groves' book, Primate Taxonomy. Eventually the group decided to use the expertise of the most experienced primate taxonomist present at the workshop, Douglas Brandon-Jones, who also happened to be the lead author of the above mentioned document, which now has been published in the International Journal of Primatology. The group of South Asian primate field biologists accepted the langur subspecies definitions proposed by PSG and Doug as opposed to the species as defined by Colin Groves. However, since there was much confusion in delimiting boundaries for the various subspecies, it was agreed to rely on Doug's study of all museum specimens during his subsequent visit to BNHS and some field sites in the final assessment. The paper presented in this issue of ZPJ is a result of the extensive study of specimens which Doug has carried out in his taxonomic career. The final report of the status of South Asian primates in the CAMP Report also follows the same taxonomy as this paper for the Indian langurs.

This year, after the finalisation of the assessments, the status of endemic South Asian primates have been updated on the IUCN Red List of Threatened Species, which will be reflected in the 2004 edition. The assessments have taken a long time to get on the Red List although the status was decided and reported to IUCN Red List Authority and focal point last year itself. The reason for this is that the IUCN Red List has an elaborate and cumbersome process of reviewing assessments. While the process justifiably produces consistency, it also delays inclusion of status, or updation sometimes for years. The system of getting a species included in the Red List after evaluation is to submit it for checking by the Red List focal point which is appointed within each Specialist Group of SSC, IUCN. The focal point checks for consistency and details and then passes on the accepted or revised assessment to the Red List authorities for inclusion in the forthcoming list. There are flaws in the process however. The first is delay, as stated above, which could, in fact, also delay conservation action at the ground level, that might aid survival of the species. The second flaw is the "four walls" approach with the assessments relying on the focal point's perception of the ground situation thousands of miles away. Unless the red list focal point has field experience in the region where the species is found or very good contacts with local biologists, he/she may not be aware of various plausible scenarios there. This can lead to misunderstanding of the suggested assessment and wrongful modification. The SSC has been accused of this top-down, time-consuming approach for a long time, which has in one sense resulted in the global assessment exercises, such as the Global Amphibian Assessment, and the same for Mammals, Freshwater Biodiversity, Reptiles, etc. which have ambitious intentions of assessing all known species, respectively, from around the world. While the "jury" is still out on the Global Assessments, which have not been completed or published as yet, it has been noted by collaborators that the Global Assessment programme, in its enthusiasm to utilise and be consistent with the SSC's long-awaited and ambitious global data base, the Species Information System (SIS), that the Global Assessment programme does not bring as much information to the Red List criteria for making accurate assessments as some other methods. Thus, the Global Assessment methodology itself has to be assessed.

Printed below are the IUCN status of langurs and leaf monkeys assessed at the South Asian Primate CAMP workshop and dealt with by Douglas BrandonJones in his paper in this issue.

\section{Taxa $\quad$ IUCN Status \& Criteria Rationale}

1. Semnopithecus johnii johnii VULNERABLE C2a(i) Widely distributed langur in the Western Ghats but threatened due to habitat loss, fragmentation, human interference and hunting. Number of mature individuals is estimated to be around 8,300 in a restricted range of less than $20,000 \mathrm{~km}^{2}$. Since no subpopulation contains more than 1000 mature individuals, the taxon is Vulnerable due to small numbers. The decreasing area and quality contribute to Vulnerable category for restricted range.

2. Semnopithecus entellus achates LEAST CONCERN This taxon has the widest distribution of all the subspecies of Semnopithecus entellus group, occurring in more than 50 recorded locations. Although there are concerns of its conflict with humans and some doubts on the peripheral populations as being hybrids with other subspecies, this taxon is less threatened from external factors and therefore considered Least Concern.

3. Semnopithecus entellus ajax CRITICALLY ENDANGERED B1ab(iii,v)+2ab(iii,v)

locality in India and in one locality in Nepal. Due to the threats to the taxon in India, it is Critically Endangered.

4. Semnopithecus entellus anchises NEAR THREATENED Not much is known about this subspecies since it is recorded from only a few locations. It is likely that the range of the taxon, although very wide is actually restricted to fewer locations that are exposed to changing habitat patterns and use, making this a more vulnerable taxon. It is therefore categorised as Near threatened compared to S.e. achates.

5. Semnopithecus entellus entellus NEAR THREATENED This taxon is widely distributed occurring in $>35$ recorded locations. Althought there are concerns of its conflict with humans and some doubts on the peripheral populations as being hybrids with other subspecies, this taxon is less threatened from external factors and therefore considered Near Threatened.

\section{Semnopithecus entellus hector ENDANGERED B2ab(i,ii,iii,iv,v)}

This taxon has a disjunct distribution within the lower elevations of Himalaya, restricted in its area of occupancy and threatened by human activities. The number of individuals is also restricted and declining due to which the taxon is Endangered.

7. Semnopithecus entellus hypoleucos ENDANGERED B2ab(ii,iii) The subspecies has a restricted range and area with a fragmented distribution. With the forests of the Western Ghats being threatened and degraded, the status of this taxon is threatened and is categorised as Endangered.

8. Semnopithecus entellus schistaceus NEAR THREATENED The taxon although widely distributed across the Himalaya, is subject to various threats from human interference, logging, habitat loss, fires, human habitations, expansion, developmental activities, encroachment, war, etc., which makes it susceptible to declines in areas subject to such threats. Hence categorised as Near Threatened.

9. Semnopithecus priam priam

VULNERABLE B2ab(i,ii,iii,iv,v)

This subspecies is distributed widely, south of river Krishna in Andhra Pradesh to Madurai in Tamil Nadu, but the area of occupancy is very few and far in between. Due to its highly fragmented distribution and threats on its habitats, the taxon is susceptible to declines at various localities and hence categorised as Vulnerable.

10. Semnopithecus priam thersites ENDANGERED in India B2ab(i,ii,iii,iv,v) This subspecies is distributed south of Palghat Gap in the Western Ghats foothills, with restricted area of occupancy. Due to its highly fragmented distribution and threats to its habitats and populations, the taxon is categorised as Endangered. population and is also under severe pressure due to various threats to the habitat. The rate of decline in the population is correlated to habitat loss, which is $>50 \%$ over 3 generations and is likely to decline in the future over the next 10-20 years. 